\title{
Aligning Digital Storytelling to The TPACK Framework: A Learning Experience for Pre-Service Teachers in A Learning-By-Designing Project
}

\author{
Cátia Luzia Silva Harriman ${ }^{1}$, Robert Maribe Branch ${ }^{2}$ \\ ${ }^{1}$ Instituto UFC Virtual - Universidade Federal do Ceará (UFC) - Campus do Pici \\ Bloco 901, 1o andar, CEP: 60.440-554 - Fortaleza, CE - Brazil \\ ${ }^{2}$ Department of Educational Psychology and Instructional Technology - The University \\ of Georgia \\ Athens, U.S.A. \\ catia@virtual.ufc.br, rbranch@uga.edu
}

\begin{abstract}
This article describes research that explored the role that the TPACK (Technological Pedagogical Content Knowledge) framework had on digital storytelling, a design-based learning opportunity for pre-service teachers taking a technolgy integration course. The results indicated that there were gains in the technological pedagogical and content knowledge of the preservice teachers involved in the research and that they acquired a holistic view of the process of teaching with technology, as a consequence of their participation in the designed digital storytelling project.
\end{abstract}

\section{Introduction}

Prospective teachers face new challenges in contemporary schooling. Learning how to teach nowadays involves not only the traditional roles of classroom management, knowledge of teaching techniques and observance to curriculum goals, but also how to potentially enhance the learner's educational experience with the technological affordances found in today's world. The existence of the Internet, web-based resources, and multimedia tools has increased this challenge.

Technology is becoming more present in the lives of pre-service teachers. However, the pedagogical use of technology is not inherent to the acquisition of the tool itself. The personal uses that prospective teachers make of technology do not necessarily have the same application in the educational context. Mishra and Koehler (2006) agree with this notion when they state "merely knowing how to use technology is not the same as knowing how to teach with it" (p. 1033). Therefore, the use of technology for teaching and learning involves an educational process that makes expertise evolve as a consequence of responsibly designed learning opportunities.

This study stresses the importance of viewing technology as a tool to enhance learning. The efficient use of technology in the educational context may enhance learning, contributing to more creative processes and serving as a cognitive tool (Jonassen \& Reeves, 1996). However, the effective use of technology as a cognitive tool will depend on the efficient pedagogical preparation of prospective teachers, reaching beyond technical skills acquisition. The purpose of this study was to investigate the impact that digital storytelling, a design-based learning opportunity, had 
on the technological pedagogical content knowledge of teachers taking a pre-service technology integration course at a southeastern american university.

\subsection{Rationale}

Positive change in the way technology is used in the classroom has its roots in teachers' pre-service education. Willis (1997) proposed an alternative strategy in the way teachers are prepared, claiming that teachers must be trained to learn with computers, not about computers. Bransford, Darling-Hammond and LePage (2005) agree that there is the need for a new type of knowledge that meets the needs of changing times.

The preparation of prospective teachers to use technology must create opportunities for meaningful uses of technology as a tool to enhance learning. Moreover, pre-service teachers need to construct a clear vision of how to integrate technology into their teaching, going beyond the mere development of technical skills. Ertmer, Conklin, Lewandowski and Osika (2003) state: "In order to translate skills into practice, teachers need specific ideas about how to use these skills to achieve meaningful learning outcomes under normal classroom conditions" (p. 96). The educational process focused solely on the development of skills is connected to a technology-centered approach to educational technology where its pedagogical potential is disregarded.

Insufficient modeling of effective instructional practices in pre-service teachers' education remains a problem, however. New approaches need to be offered in order to improve the pre-service teachers' ability to integrate technology into their teaching. One of these new approaches is Mishra and Koehler's (2006) Technological Pedagogical Content Knowledge (TPCK or TPACK) framework. The authors explain that teacher education should emphasize three types of knowledge: knowledge of technology (skills related to the operation of standard and advanced technologies - TK), knowledge of pedagogy (methods of teaching - PK) and knowledge of content (subject matter - CK). The TPACK approach was appropriate for this study because it offers a holistic framework to study the integration of technology in pre-service teacher's education. Furthermore, the TPACK framework explains the three types of knowledge individually, and the ways in which the three types of knowledge interact with each other (three pairs of knowledge intersection) and how they all interact together (one triad) (Mishra \& Koehler, 2006; Barbour, Rieber, Thomas \& Rauscher, 2009). Figure 1 illustrates the way each type of knowledge in the framework intersects with the other types of knowledge.

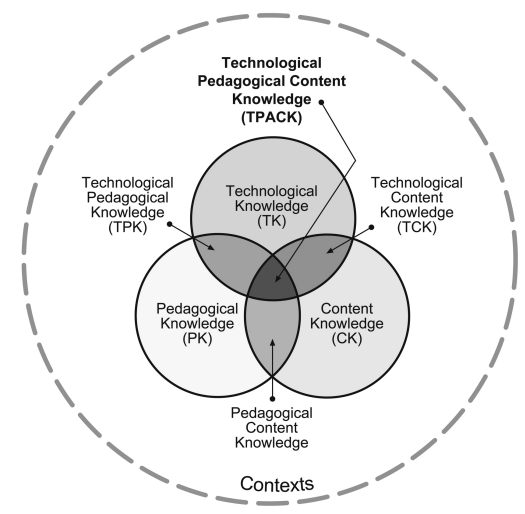

Figure 1. The Technological Pedagogical Content Knowledge Theoretical Framework. Source: http://tpack.org/ 
Pedagogical content knowledge refers to the methods of teaching that are applicable to specific contents. Technological content knowledge is related to the possible representations of content through the affordances of technology. Technological pedagogical knowledge addresses the reciprocity between processes and methods of teaching and technology. Finally, technological pedagogical content knowledge (TPACK), as defined by Mishra and Koehler (2006) is:

The basis of good teaching with technology and requires an understanding of the representation of concepts using technologies; pedagogical techniques that use technologies in constructive ways to teach content; knowledge of what makes concepts difficult or easy to learn and how technology can help redress some of the problems that students face; knowledge of students' prior knowledge and theories of epistemology; and knowledge of how technologies can be used to build on existing knowledge and to develop new epistemologies or strengthen old ones. (p. 1029)

Mishra and Koehler (2006) also argue that the TPACK theoretical framework is directly related to practice, in learning by doing, as teachers engage in learning technology by design.

Digital storytelling practices, for instance, can be used in accordance with such approach and figure as an alternative tool to boost prospective teachers' contact with technology in several different levels, providing them with opportunities to experience real constructivist learning as they design their stories. The intersection of TPACK and digital storytelling resides on the fact that technology can be used in the classroom to promote meaningful learning opportunities.

Storytelling can be used as a learning tool and it has gained increased popularity in higher education (McDrury \& Alterio, 2003). New views on the nature of learning and the importance attributed to reflection in education have led these authors to develop a five-stage learning process through storytelling. Storytelling is embedded in human experience. Schank (1995) states that thinking is related to how we explain reality through storytelling. A story - personal, someone else's or conversational represents one's own struggle to understand and explain the world, building knowledge. Teachers are, in fact, frequent storytellers. Storytelling is in the center of the teaching process and that author adds: "A good teacher is not one who explains things correctly but one who encourages explanations in a memorable (i. e., interesting) format" (Schank, 1995, p. 15). Storytelling seems to be an inherently educational activity. McDrury and Alterio (2003) define storytelling as follows:

Storytelling is a uniquely human experience that enables us to convey, through the language of words, aspects of ourselves and others, and the worlds, real or imagined, that we inhabit. Stories enable us to come to know these worlds and our place in them given that we are all, to some degree, constituted by stories: stories about ourselves, our families, friends and colleagues, our communities, our cultures, our place in history. (p. 31)

Combining the ancient tradition of telling stories with the technological affordances of today's world, digital storytelling figures as one possibility for engaging 
pre-service teachers in projects that place technology as a meaningful tool for teaching and learning. Robin (2008) remarks that digital storytelling is not a new idea among educational practices. However, digital Storytelling has benefited from the growing affordability and easy access to multimedia resources tools (cameras, computers, microphones, editing software, scanners), expanding the possibilities of the oral tradition, and has proved to be a practical and simple way to promote authorship among students and teachers. McLellan (2007) defines digital storytelling as "the art and craft of exploring different media and software applications to communicate stories in new and powerful ways using digital media" (p. 66). While developing multi-literacies, such as media literacy, digital literacy, and visual literacy when dealing with digital images, text and sound to construct narratives, pre-service teachers are faced with the opportunity of being creators of educational product content.

This study intended to explore the role that the TPACK framework has on digital storytelling, a design-based learning opportunity for teachers taking a pre-service technology integration course. The delimitations of the study (aspects that keep the work manageable) refer to the population and to the scenario chosen for the study - this study is limited to pre-service teachers enrolled in a technology introduction course at a Southeastern American university. The main research questions are:

1)What is the description of the process of designing digital stories when preservice teachers use the TPACK framework?

2)What are the pre-service teachers' perceptions of the TPACK framework as it relates to their projects?

3)How do instructors perceive the effectiveness of the TPACK framework in the design of their students' digital stories?

The results of this study should directly benefit prospective teachers and teacher educators in general because it has the potential to demonstrate the benefits of multimedia projects for pre-service teachers.

\section{Research Method}

The qualitative method was the adequate choice for the present case study, because the perceptions and the constructed meanings of the participants were the focus of the investigative process.

In order to assure the internal validity of the research, some strategies were applied from the very beginning of the research planning. For instance, triangulation was performed. Despite the fact that "triangulation" is a controversial term (Bogdan \& Biklen, 2007), it deals with a concept that was used in this research. According to Merriam and Associates (2002), "In this triangulation strategy, the researcher collects data through a combination of interviews, observations and document analysis" (p.25). The benefit of such strategy resides in the possibility of making a pooled evaluation of data.

The participants in the study were composed of a purposive sample. This means that a sample that was more likely to offer real, detailed and rich information about the subject of the study was selected among pre-service teachers and their instructors at a Southeastern American university attending four sessions of its Introduction to Computers for Teachers course during the Spring Semester of 2010. A typical 
Introduction to Computers for Teachers class receives around 20 students and is composed mainly by first or second year students from the College of Education, although the course does accept students from other fields. Usually an incoming student in this Introduction to Computers for Teachers has basic knowledge of productivity tools such as word processor and presentation software. Basic Internet skills such as browsing the web, sending and receiving e-mail, and using a search engine are also common in this population. Working with digital pictures also occurs at a very basic level. However, working with digital video, creating web pages and planning lessons are skills not commonly found among the students.

There was a balance in the number of pre-service teachers attending the four sessions being studied during this research: 14 at the 8:00 a. m session; 12 at the 9:30 one; 15 at 11:00 a.m., and 13 at 12:30. The majority of the students were female $(77.8 \%$ ) against $22.2 \%$ of males. Regarding their year in college, most students were Juniors (35.2\%). Also, $90.7 \%$ of the students' age ranged from 18 to 22 years old.

\subsection{Data Collection Tools and Procedures}

The primary resources for data collection were interviews with pre-service teachers and the instructor, observations of class activities, surveys, and artifacts analysis - artifacts analysis involved course web portfolios and digital stories developed by the pre-service teachers, as well as any handouts provided by the instructor such as the peer review form. As for surveys, there was the Background Information Form - an instrument to collect data on general demographic information about the students, as well as information on the level of knowledge on various technology tools. There was also The Survey of Preservice Teachers' Knowledge of Teaching and Technology, developed and validated through the collaboration between Iowa State and Michigan State universities (available at http:www.tpack.org) to be used as is or modified. It was administered electronically twice: before and upon conclusion of the digital storytelling project, with pertinent modifications to the demographic section of the form.

The purpose of the TPACK survey was meant to be twofold - to raise awareness of the pre-service teachers' level of knowledge of different aspects of TPACK and to detect any changes on those levels. Although determining the development of TPACK was outside the scope of this research, the survey was used to help determine the usefulness of the use of the TPACK framework in the digital storytelling project. Due to small participation in the two rounds of the survey (54 participants in the first round and 47 in the second one), however, major conclusions could not be drawn from this data source.

The data collection process used activities originally planned for class assignments, such as software tutorial, practice activity, final project development, and so on. The only activity planned to take extra time (outside class activities) was the interview with students. Interviews did not take more than one hour and were scheduled at the student's convenience. These arrangements were made in agreement with the course instructor.

\subsection{The Digital Storytelling Implementation Plan}

When the digital storytelling project started, the course had already offered knowledge background to the pre-service teachers on a variety of technology tools, instructional 
resources and basic educational psychology foundation. For this project, the students could choose their digital storytelling tool: Storybird (http://storybird.com/), VoiceThread (http://voicethread.com/), PhotoStory, or iMovie. The tools mostly used were VoiceThread and iMovie.

The digital storytelling activity proposed in this research added the TPACK element to the instruction. The assignment applied Mayer's "SOI" framework to its instructional design: 1) S: Selecting relevant information to be retained and processed in working memory, 2) O: Organizing incoming information in coherent pictorial and verbal representations, and 3) I: Integrating incoming information with existing knowledge. (Mayer, 1999) Each part of the assignment tried to address this framework. For instance, students selected relevant information in "Planning Your Story." They then organized information in "Identifying, Gathering, and Editing materials". The integration of information occurred in "Development and Implementation."

Furthermore, the design of the activity applied Mayer's principles to an adaptation of the five-phase media production process outlined by Ohler (2008): 1) Planning; 2) Identifying and gathering materials, expertise; 3) Development and implementation; 4) Honing, editing, and finalizing; 5) Sharing with others. This author recognizes, however, that this is "a fairly generic treatment of this process" (Ohler, 2008, p. 136). Because the bulk of Ohler's work occurs in the K-12 setting, Ohler's framework was adapted to fit the characteristics of the students in pre-service teacher technology integration course, resulting in the process outlined in Figure 2.

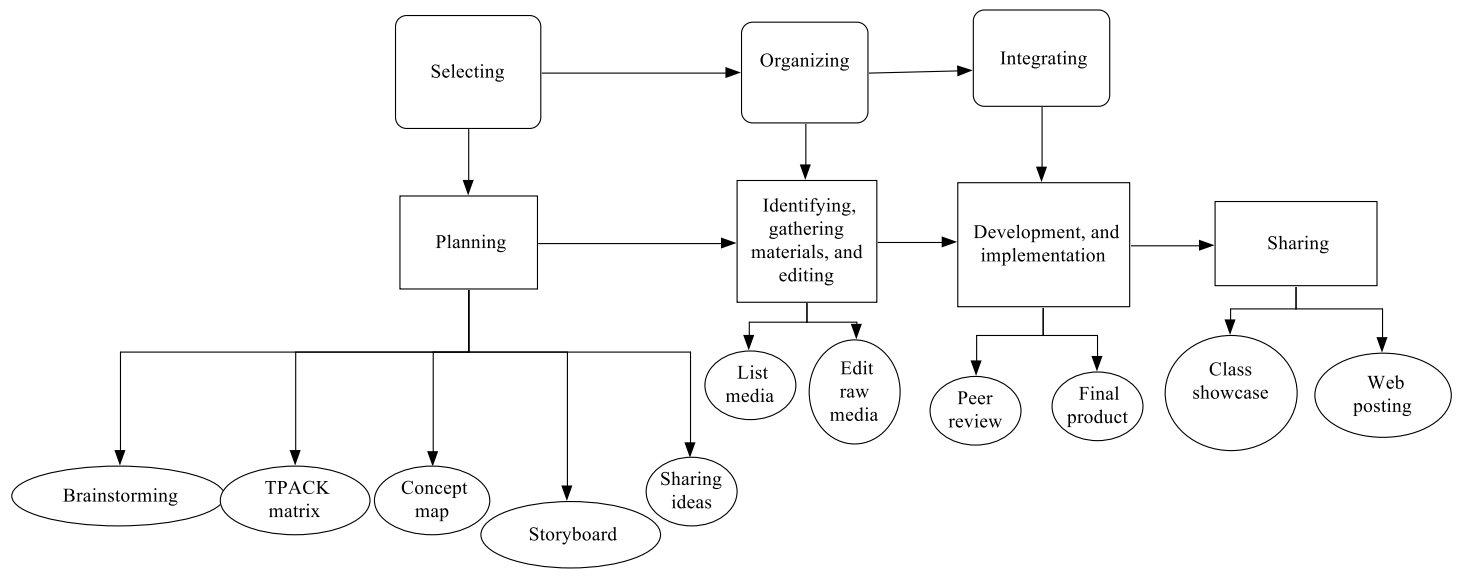

Figure 2. Digital Storytelling assignment process, adapted from Mayer (1999) and Ohler (2008)

\subsection{Data Analysis}

Data was analyzed inductively, according to the concepts of the underlying theoretical framework. Specifically, triangulation of multiple data sources was used to guarantee the internal validity of the research. All interviews were transcribed using Express Scribe software and organized with Microsoft Word®, a method developed by Dr. Ruona to help analyze data. Ultimately, all interviews were coded and compiled using a master table, making it possible to sort the data in different ways (Ruona, 2005). The TPACK framework was used to develop categories. However, there was flexibility to accommodate different categories that might have risen from the data. 


\section{Main Results and Discussion}

Regarding the first research question (What is the description of the process of designing digital stories when pre-service teachers use the TPACK framework?), the Digital Storytelling Project implementation plan occurred without major discrepancies. It required one extra day due to the dynamics of that particular context, but it provided a supporting structure to the overall project development and showed that skills necessary for its accomplishment could, indeed, be taught in sequence, building upon the skills from previous steps. It was also flexible enough to have the students experience the process in a personalized manner, as, in fact, they did. One of the students expressed the idea that she was too ambitious in the beginning and that she soon realized that she had to adapt her amount of information in order to fit a two to three-minute video. She then decided to use her digital story as an introduction to unit in History. Another student, instead of choosing a standard first, then deciding on a story and finally going to try to find the right pictures, did it the other way around. She first found on Storybird an appealing artist scenario with pictures of fruits and vegetables. She then built her story around a health standard from there.

Considering the experience of developing a digital story as a whole, it was a very enjoyable opportunity for the students, according to the opinions expressed in the interviews and also in the students' portfolios. A student said: "I did enjoy it! (...) I like that it was straight forward, just make something that you could use, and I could teach in a classroom setting, and it was fun." The students also felt proud of their finished products. Furthermore, the students learned a plethora of hardware and software skills, building on previous knowledge. Most students who were interviewed felt comfortable with the technological tools used during the project.

Pedagogically, in comparison with previous digital story experiences developed in the course, there was a gain in pedagogical quality. The level of the themes being explored was higher and the stories were more focused on instructional objectives. When asked in their reflections what they wanted their students to achieve through their digital stories, the pre-service teachers answered: "I want students to be able to write creatively and comprehend what they are writing", or: "I want students to be able to use technology to create their own literature." During the interviews, digital storytelling was regarded as "more enjoyable", "more interesting", or "more memorable" way of teaching. Digital storytelling was also mentioned as a way to motivate students to be creative and develop their own stories to teach each other. Regarding content, students believed that digital storytelling is an effective method to introduce a new topic to the students or to review one. It can also be used to simplify topics.

The main results for second research question (What are the pre-service teachers' perceptions of the TPACK framework as it relates to their projects?) showed that the students considered the TPACK framework used in the Digital Storytelling project as a good general guideline and saw how it could be integrated in other projects throughout the course. The framework was also considered valuable for the way it helped novices while integrating technology in the classroom. The use of the concept mapping tool was seen by the participants as the most useful resource during the development of the project. All interviewed students consider that they learned to develop a meaningful product that they can use in their future classrooms, having the TPACK as a guide. One of the students stated: "The framework basically just keeps us 
from straying off too far, to making sure to keep it educational and keep it informational, and not basically give kids a laser show without reason." Another student expressed her thoughts about the usefulness of the framework this way: "I think that this [the framework] helps pull the focus into why are you using technology in the classroom. I can show a movie or a slide show all day long but if it's not focusing on what they need to be learning for that grade level on that semester or what they need to take away from it, then it's useless."

As for research question three (How do instructors perceive the effectiveness of the TPACK framework in the design of their students' digital stories?), it can be indicated that: the instructor of the course considered that she had a very good experience in the digital storytelling project this time, compared to previous experiences. According to her, in other semesters this is how she worked: "I would let them write a story, kind of about anything, so they're really comfortable learning the tool, they don't have to worry about the content, they just worry about the tool. And so what happens is the actual end project is not very good." However, she understands that introducing the TPACK framework to the students that semester has brought positive change to the course. She explained: "Using that I think gave more structure to what has been a project that did not have the structure that it needed. So, I think that their stories are more much like stories this time, they are much more focused on content, or curriculum, that they have been in the past. They were better just in general, but I think they really took the hard parts of the TPACK model (...). Because I would say, well, the students did a good job." The instructor also considered that students focused more on content and that they have become independent learners, finding alternative ways around technology.

The results also showed that, due to the alignment of the TPACK framework with a learning-by-design instructional design approach, the participants in the present research revealed feeling secure and motivated to implement digital storytelling practices in their future classrooms. A level of reported self-confidence was detected. The pre-service teachers also expressed the desire to extend their knowledge to future peers in their professional circle. This brings immediate practical consequences to preservice teacher's technology integration education: teacher education institutions should consider, therefore, the adoption of design-based projects based on the TPACK framework.

Although being fun was not the fundamental objective of the digital storytelling project, it played an important role in having the participants motivated to engage in the activities. The students felt that they could express themselves and be creative. As for instructional materials, the use of storyboards was not a common choice among the preservice teachers and they preferred to use the concept mapping tool with guiding questions based on the TPACK framework.

The participants have demonstrated gains in all aspects of the TPACK framework, despite the fact that there were different levels of TPACK development among them, as shown in their artifacts. This research has also detected that pre-service teachers, upon instruction, had several ideas of how to integrate technology in their classrooms and viewed technology as a tool for assisting learning. Above all, they realized that it was important to put technology in their future students' hands. 
Therefore, the introductory technology course can serve as a useful context for introducing TPACK.

Being comfortable with technological tools is the base for connecting a specific content area, such as Science, and technology. The Science pre-service teachers in this research were able to use the technology to structure their stories. They could also cite a number of different topics in Science that could benefit from the use of digital storytelling in the classroom.

Upon their participation in the Digital Storytelling project, pre-service teachers became more independent learners, acquired a set of technological skills and felt proud of their final artifacts. As a result, they felt motivated to implement digital storytelling practices in their future classrooms. They also believe that digital storytelling can be an efficient way to work curricular content with students, in a more memorable and fun way, meeting the learning needs of different student groups.

Some limitations in this research existed: the participants' incipient level of pedagogical knowledge; the participants' possible fear of a negative impact on their course grades as a consequence of making comments about the digital storytelling experience; the impossibility of the generalization of the results of this research because students from four sessions of the same instructor were studied; the large amount of data, which multiplied the complexity of data analysis.

There are four implications for future research: the first is to compare an inservice teachers' digital storytelling experience with that from his/her pre-service time. The second is to detect the impact of teachers' digital storytelling practices on their students' performance. The third is to study how the alignment of the TPACK framework and digital storytelling impacts pre-service teachers' understanding of specific content areas. The fourth is to examine how the alignment of the TPACK framework and digital storytelling impacts pre-service teachers' understanding of student assessment practices in specific content areas.

\section{Conclusions}

The results of this research indicated that there were gains in the technological, pedagogical, and content knowledge of the pre-service teachers involved in this research as a consequence of their participation in the designed digital storytelling project.

The instructional design used in the digital storytelling project was effective and the integration of the TPACK framework figured as a secure guide, providing confidence to the pre-service teachers. The instructor who participated in the research saw the importance of using TPACK not only in one project, but throughout the entire course.

The use of the TPACK framework during the development of digital storytelling impacted positively the development of the projects created by prospective teachers, benefitting their college teacher education.

\section{References}

Barbour, M., Rieber, L. P., Thomas, G., and Rauscher, D. (2009) Homemade Powerpoint Games: A Constructionist Alternative to Webquests. (2009). TechTrends, 53(5), 54-59. 
Bogdan, R. C., and Biklen, S. K. (2007) Qualitative Research in Education: An Introduction to Theory and Methods ( $4^{\text {th }}$ ed.). Boston: Allyn and Bacon.

Bransford J., Darling-Hammond, L., and LePage. (2005) Introduction. In L. Darling, \& J. Bransford. Preparing Teachers for A Changing World: What Teachers Should Learn and Be Able To Do. San Francisco, CA: Jossey-Bass.

Ertmer, P. A., Conklin, D., Lewandowski, J., and Osika, E. (2003) Increasing Preservice Teachers' Capacity for Technology Integration through the Use of Electronic Models. Teacher Education Quarterly, 30, p. 95-112.

Harriman, C. L. S. (2011) The Impact of TPACK and Digital Storytelling as A Learning Experience for Pre-Service Teachers in A Learning-By-Designing Project. Doctoral Dissertation. The University of Georgia, Athens, USA.

Jonassen, D. H., and Reeves, T. C. (1996) Learning with Technology: Using Computers as Cognitive Tools. In D. H. Jonassen (Ed.), Handbook of Research on Educational Communications and Technology (1st ed.) (pp. 3-36). Mahwah, NJ: Lawrence Erlbaum Associates.

Mayer, R. E. (1999) Designing Instruction for Constructivist Learning. In C. M. Reigeluth (Ed.), Instructional Design Theories and Models. Vol. II, A New Paradigm of Instructional Theory (pp. 141-159). Mahwah, N.J.: Lawrence Erlbaum.

McDrury, J., and Alterio, M. (2003) Learning through Storytelling in Higher Education: Using Reflection \& Experience to Improve Learning. London: Kogan Page.

McLellan, H. (2007) Digital Storytelling in Higher Education. Journal of Computing in Higher Education, 19(1), p. 65-79. (ERIC Document Reproduction Service No. EJ830801) Retrieved August 3, 2009, from ERIC database.

Merriam, S. B . and Associates. (2002) Qualitative Research in Practice - Examples for Discussion and Analysis. San Francisco, CA: Jossey-Bass

Mishra, P., and Koehler, M. J. (2006) Technological Pedagogical Content Knowledge: A Framework for Teacher Knowledge. Teachers College Record, 108(6), 1017-1054.

Ohler, J. (2008) Digital Storytelling in the Classroom: New Media Pathways to Literacy, Learning, and Creativity. Thousand Oaks, CA: Corwin Press.

Robin, B. R. (2008) Digital Storytelling: A Powerful Technology Tool for the 21st Century Classroom. Theory Into Practice, 47(3), 220-228. Retrieved March 23, 2009, from http://www.informaworld.com/10.1080/00405840802153916

Ruona, W. E. A. (2005) Analyzing Qualitative Data. In R. A. Swanson \& E. F. Holton (Eds.), Research in organizations: Foundations and methods of inquiry (pp. 223263). San Francisco, CA: Berrett-Koehler.

Schank, R. C. (1995) Tell Me a Story: Narrative and Intelligence. Rethinking Theory. Evanston, Ill: Northwestern University Press.

Willis, E. M. (1997) Technology: Integrated into, not Added onto, the Curriculum. Experiences in Pre-service Teacher Education. Computers in the Schools, 13(1-2), 141-53. 